\title{
Produção industrial e vazamento de demanda para o exterior: uma análise da economia brasileira *
}

\author{
Marília Bassetti Marcato \\ Fernanda Oliveira Ultremare ${ }^{* * *}$
}

\begin{abstract}
Resumo
O cenário de desaceleração do crescimento econômico tem suscitado discussões a respeito do crescente vazamento de demanda da economia brasileira para o exterior, uma vez que haveria um descompasso entre produção industrial e demanda doméstica. Ao considerar as transformações na relação entre produção e comércio internacional, este artigo extrapola os indicadores tradicionalmente utilizados para mensurar a demanda doméstica por bens industriais, avançando na caracterização do vazamento de demanda. A partir de matrizes insumo-produto, propõe-se uma forma complementar de análise dos coeficientes de penetração das importações e insumos importados. Os estímulos gerados pelo aumento na importação (e produção) de um setor específico não se propagaram pela matriz produtiva brasileira com mais força, apontando para o desadensamento da matriz produtiva. Ao mesmo tempo, o multiplicador de vazamento de demanda aponta para a deterioração da capacidade produtiva doméstica acomodar acréscimos de demanda. Dessa forma, o estudo retrata o esgarçamento do tecido industrial brasileiro.
\end{abstract}

Palavras-chave: Vazamento de demanda; Análise insumo-produto; Cadeia global de valor; Produção industrial; Economia brasileira.

\begin{abstract}
Industrial production and demand leakage: an analysis of the Brazilian economy

The scenario of economic slowdown has raised discussions about the growing demand leakage in the Brazilian economy, given the resultant gap between industrial production and domestic demand. By considering the recent changes in the relationship between industrial production and international trade, this paper goes beyond the indicators traditionally used to measure domestic demand for industrial goods. Using input-output tables estimated annually, we explore a complementary way to analyze both the penetration of imports and the imported inputs coefficients. The stimuli generated by an increase in imports (and production) of a specific sector have not been spread, with greater intensity, by the Brazilian productive matrix, pointing to a regression in the productive matrix. Meanwhile, the demand leakage multiplier indicates a sharp deterioration of the domestic productive capacity to accommodate increases in domestic and foreign demand. Thus, this study portrays the worsening of the Brazilian industrial scenario.
\end{abstract}

Keywords: Demand leakage; Input-output Analyses; Global value chain; Industrial production; Brazilian economy.

JEL F14, L16, O54, D57.

\footnotetext{
*Artigo recebido em 10 de agosto de 2016 e aprovado em 7 de agosto de 2017.

${ }^{* *}$ Pesquisadora associada do Núcleo de Economia Industrial e da Tecnologia do Instituto de Economia da Universidade Estadual de Campinas (Neit/IE/Unicamp), Campinas, SP, Brasil. E-mail: ma bassetti@hotmail.com.

${ }^{* * * *}$ Professora associada da Faculdade de Ciências Econômicas da Universidade Federal do Rio Grande do Sul (FCE/UFRGs), Porto Alegre, RS, Brasil. E-mail: feultremare@gmail.com.
} 


\section{Introdução}

A literatura estruturalista (Furtado, 1964, 1967; Prebisch, 2000; Singer, 1950) e a abordagem keynesiana-kaldoriana (Dixon; Thirlwall, 1975; Kaldor, 1989; Mccombie; Thirlwall, 1994; Thirlwall, 1968, 1979, 2005) destacam o papel fundamental da demanda e seus efeitos multiplicadores de renda sobre a produção de outros setores da economia na geração de um círculo virtuoso de crescimento econômico. Tais efeitos estariam condicionados à organização da estrutura produtiva, aos encadeamentos para frente e para trás e à dinâmica de oferta doméstica e externa. Nesse sentido, uma matriz produtiva mais densa e integrada permitiria impedir um possível vazamento de demanda doméstica para o exterior, fazendo com que essa seja acomodada domesticamente como demanda interindustrial.

O recente cenário de desaceleração do crescimento econômico tem suscitado discussões a respeito de um crescente vazamento de demanda agregada da economia brasileira para o exterior sob a forma de importações de bens e serviços. Na literatura, as análises do recente descompasso entre produção industrial doméstica e demanda doméstica mostram a dificuldade em construir medidas que representem adequadamente o comportamento da demanda de bens e serviços (Bastos et al., 2015; Carvalho; Ribeiro, 2015; Medeiros, 2015; Serrano; Summa, 2012, 2015).

O objetivo deste estudo é avançar na caracterização do vazamento de demanda doméstica da economia brasileira sob a forma de importação de bens e serviços para o período de 2000 a 2013. Ao considerar as recentes transformações na relação entre produção industrial e comércio internacional, o estudo extrapola os indicadores tradicionalmente utilizados para mensurar a demanda doméstica por bens industriais, e seu conseguinte vazamento para o exterior. A partir de matrizes insumo-produto estimadas para os anos de 2000, 2008, 2009 e 2013, o trabalho incorpora as variações de estoque na proxy de demanda doméstica. Valendo-se do nível de desagregação proporcionado pelas matrizes insumo-produto, é explorada uma forma complementar de analisar os coeficientes de penetração das importações e de insumos importados. Propõe-se, ainda, acrescentar evidências a respeito dos efeitos, diretos e indiretos, que um aumento na importação e na produção de determinado setor econômico da economia brasileira possui sobre a importação e produção da matriz produtiva brasileira (multiplicadores de importação e de produção).

O trabalho está organizado em mais três seções, além desta introdução. $\mathrm{Na}$ primeira seção, é apresentado o arcabouço analítico, destacando alguns elementos estruturais da esfera da produção. A seção dois, além de uma crítica metodológica, apresenta o tradicional retrato do vazamento de demanda sob a perspectiva do consumo aparente na economia brasileira a partir dos dados da Secex/MDIC publicados pela Confederação Nacional de Indústria (CNI). A seção três é dedicada 
aos indicadores de vazamento externo a partir das matrizes insumo-produto e, finalmente, as principais conclusões são apresentadas.

\section{Arcabouço analítico: mudanças na relação entre produção e comércio}

O comércio internacional mudou drasticamente com a emergência de sistemas de produção que atuam para além das fronteiras domésticas, comumente chamados de cadeias globais de valor (CGV). A prevalência das $\mathrm{CGV}$ nos processos de produção é considerada uma das características mais importantes da globalização econômica. No entanto, a globalização não é um processo constante pura e simplesmente impulsionado por menores custos comerciai ${ }^{1}$. A globalização, sob a perspectiva da produção e comércio, pode ser entendida como um fenômeno multifacetado situado historicamente em cenários econômicos distintos. A "primeira desagregação" (first unbundling) da globalização pautou-se principalmente na separação geográfica entre consumo e produção, e foi impulsionada por menores custos de transporte. Essa forma deu lugar a um fenômeno diferente, impulsionado por menores custos de transmissão, a "segunda desagregação" (second unbundling) da globalização (Baldwin, 2006, 2011).

A globalização como fenômeno econômico mudou, trazendo novos nuances para a relação entre produção e comércio internacional. O nível do comércio internacional como parcela da produção global quadruplicou desde 1950, ao mesmo tempo em que a parcela de conteúdo estrangeiro nas exportações brutas quase dobrou se comparada à de 1970 (International Monetary Fund, 2013). Até meados dos anos 1980, a proximidade geográfica dos vários estágios da produção industrial era uma característica relevante para a otimização do processo produtivo, uma vez que os custos de coordenação eram consideráveis, resultando na segmentação de áreas industriais e na formação de clusters locais (Amador; Mauro, 2015). A "segunda onda da globalização" levou a um aumento do comércio de peças e componentes especialmente pós-1985², o que reflete claramente o desenvolvimento de processos de produção fragmentados. Miroudot, Lanz e Ragoussis (2009) apresentam evidências desse fenômeno, indicando que os insumos intermediários representam $56 \%$ do comércio de mercadorias e $73 \%$ do comércio de serviços, e apresentam uma taxa média de crescimento anual de $6,2 \%$ para os bens e $7 \%$ para serviços, em termos

(1) Os custos comerciais incluem toda a gama de custos entre o fornecedor e o consumidor final. Por exemplo, no caso de mercadorias, seria a soma dos transportes terrestres, os custos portuários, os custos de frete e seguro, taxas e direitos, os custos não-tarifários, mark-ups de importadores, varejistas e atacadistas; no caso de serviços, incluem os custos de comunicação, barreiras comerciais como medidas não-tarifárias e os custos de coordenação (Backer; Miroudot, 2013).

(2) De acordo com Baldwin (2011), a temporização da "segunda onda de globalização" não foi definitivamente identificada, ainda que, baseado em indicadores associados à Tecnologia, Informação e Comunicação (TIC), o autor considere o período de 1985 - 1995. 
de volume, entre 1995 e 2006. Dessa forma, apesar de não ser inteiramente novo, o fenômeno da dispersão internacional da produção industrial tem apresentado nova escala e complexidade no período recente.

Vários fatores contribuíram para a expansão do comércio mundial e para o aumento da interconectividade entre os países. Ao mesmo tempo em que a dispersão espacial da produção impôs uma série de custos, a revolução das tecnologias de informação e comunicação (TICs) proporcionou menores custos de transmissão e de coordenação, viabilizando a separação geográfica das etapas de produção sem significar perda de eficiência e pontualidade. Além disso, a fragmentação da produção para além das fronteiras nacionais também foi parcialmente facilitada pelas reformas políticas de liberalização comercial, o que levou a menores barreiras comerciais, inicialmente nas economias avançadas e mais recentemente em diversos países em desenvolvimento (Riad et al., 2011). A tecnologia utilizada no processo produtivo é outro fator que tornou possível subdividir a cadeia de valor em componentes menores e mais portáteis (Athukorala, 2005). Dessa forma, a competição internacional que costumava ocorrer principalmente ao nível dos setores, passou a ser definida nos estágios da produção (Baldwin, 2011). Neste sentido, este fenômeno complexo e multifacetado tem recebido diversos nomes - fragmentação, offshoring, outsourcing, desintegração da produção, especialização intraproduto, especialização vertical e subdivisão da cadeia de valor $^{3}$ (Baldwin, 2006; Meng; Fang; Yamano, 2012). O uso desses múltiplos termos como sinônimos torna aparente a necessidade de uma análise aprofundada sobre esses distintos processos, especialmente no que diz respeito às evidências de um novo paradigma da produção industrial.

Um primeiro passo consiste em distinguir entre produtos finais e intermediários. Os produtos finais são bens e serviços consumidos (incluindo o consumo privado e público) ou investidos como bens de capital ${ }^{4}$, já os produtos intermediários continuam no processo produtivo de produtos a jusante (Horowitz; Riker, 2014; Timmer et al., 2014). Essa distinção é especialmente importante para explicar e avaliar o comércio na sua dimensão contemporânea, considerando o aumento da participação do comércio de peças e componentes no total do comércio mundial nos últimos anos.

Uma série de estudos recentes têm buscado avaliar os fatores explicativos para essa nova dinâmica do comércio de bens intermediários como o principal motor do comércio global. Miroudot, Lanz e Ragoussis (2009) argumentam que não apenas as tarifas sobre os bens intermediários têm sido menores do que aquelas sobre os

(3) Originalmente "slicing up the value chain", usado por Krugman (1995).

(4) Os bens de capital entram como um ativo fixo no processo produtivo, enquanto os bens intermediários são utilizados e incorporados no resultado final (Miroudot; Lanz; Ragoussis, 2009). 
bens finais ao longo dos últimos 20 anos, mas um movimento transfronteiriço ativo do capital, por exemplo do investimento direto estrangeiro (IDE), tem desempenhado um importante papel e, simultaneamente, a própria fragmentação da produção tem criado novos fluxos comerciais de bens intermediários. Enfatizando o componente técnico, Athukorala (2005) observa que existe uma relação de mãodupla entre a expansão da fragmentação internacional de produtos e a melhoria na tecnologia de produção/comunicação, com o primeiro resultando em menores custos de produção e rápida penetração no mercado, incentivando novos esforços tecnológicos e uma maior fragmentação do produto ${ }^{5}$.

A fragmentação, nacional ou internacional, é um termo originalmente proposto por Jones e Kierzkowski (1990) para descrever a organização dos processos de produção. Em sua pesquisa, os autores definem fragmentação como a decomposição da produção em blocos de componentes separáveis conectados por serviços. Não é necessário ressaltar que nem todos os processos produtivos possuem diversas fases fisicamente separadas e, nesse sentido, a especialização intraproduto só é possível quando a fabricação de um produto é passível de fragmentação (Arndt; Kierzkowski, 2001). A fragmentação de um processo produtivo pode assumir a forma de cadeias sequenciais (chamadas de "cobras", onde bens intermediários são enviados e incorporados sequencialmente a partir de um país para outro, até sua entrega na fase final de produção) ou de redes complexas ("aranhas", onde as peças intermediárias vêm de um número múltiplo de destinos e encontram-se em um único local, em nenhuma ordem particular) (Baldwin; Venables, 2013; Unctad, 2013). Apesar desses casos extremos, os processos de produção normalmente são uma combinação complexa de ambas as formas (Timmer et al., 2014).

Fragmentação e offshoring ${ }^{6}$ podem ocorrer simultaneamente, tanto obedecendo aos limites da estrutura de propriedade de uma determinada empresa, em um processo de integração vertical (insourcing), como em propriedades distintas (outsourcing), que pode ser definido como "a compra de insumos de fontes externas ao invés de produzi-los internamente" (International Monetary Fund, 2013, p. 4). Isso significa que as etapas da produção podem ser espacialmente separadas, mas próximas ou distantes em termos de propriedade, ou espacialmente próximas, mas

(5) O autor observa que, quando se trata da expansão da fragmentação internacional do produto, três desenvolvimentos reforçam-se mutuamente ao longo das últimas décadas: as reformas das políticas de liberalização comercial, com a remoção de diversas barreiras de comércio e de investimento; as inovações tecnológicas em comunicação e transporte, diminuindo a distância entre as nações; e as tecnologias de produção, que possibilitaram a subdivisão da cadeia de valor em componentes menores e mais portáteis.

(6) Offshoring envolve apenas uma alteração na localização geográfica, e não na propriedade da empresa (Miroudot; Lanz; Ragoussis, 2009). 
organizacionalmente separadas ou integradas por propriedade (Arndt; Kierzkowski, 2001; Cattaneo et al., 2013; Miroudot; Lanz; Ragoussis, 2009) ${ }^{7}$.

É importante notar outra diferença conceitual entre os termos frequentemente utilizados como sinônimos: global sourcing e international outsourcing. O que distingue os dois termos é justamente a estrutura organizacional inicial da empresa: no primeiro caso, o produto ou serviço é fornecido por um fornecedor externo presente no mercado doméstico; no segundo caso, trata-se da empresa, dentro de suas próprias fronteiras organizacionais, produzindo no mercado doméstico; e em ambos os casos, a mudança ocorre de um fornecedor doméstico para outro, estrangeiro (Miroudot; Lanz; Ragoussis, 2009). Enquanto isso, a produção offshore, ou seja, a terceirização externa e o IDE, tornou-se uma prática comum para diversas indústrias, incluindo a eletrônica e a automotiva, nas quais os produtos finais podem ser divididos em componentes discretos produzidos separadamente, facilmente transportados e montados em locais de baixo custo (Unctad, 2013). Quando os processos de produção são divididos em fases subsequentes e espacialmente separados, eles podem agora ser realizados onde estão os menores custos de cada componente. Alguns estudos indicam que o nível de fragmentação será determinado por características técnicas dos produtos e pelos custos incorridos quando as etapas produtivas estão dispersas em locais diferentes, especificamente trata-se de um trade-off entre menores custos de produção e maiores custos de coordenação (Backer; Miroudot, 2013; Jones, Ronald W.; Kierzkowski, 2001).

As cadeias globais de valor tornaram-se amplamente difundidas e, com os bens intermediários atravessando as fronteiras múltiplas vezes, os processos de produção passaram a exibir uma necessidade crescente de coordenar seus múltiplos estágios. Esse processo levou ao aumento do conteúdo de serviços nos produtos manufaturados, dada a necessidade de conectar as etapas produtivas e garantir uma maior diversidade e customização dos produtos (Maurer; Degain, 2010). Como consequência, os serviços passaram a ocupar uma parcela crescente do conteúdo doméstico do produto industrial quando comparado com a manufatura per se, especialmente nos países avançados ${ }^{8}$.

(7) Alguns estudos argumentam que a fragmentação internacional da produção cria um forte nexo comércio-investimento (International Monetary Fund, 2013; Unctad, 2013). Também é possível dizer que esse nexo tem outro importante determinante, a estrutura de propriedade da empresa. De acordo com Arndt e Kierzkowski (2001), em estruturas transfronteiriças de produção onde a propriedade separada não é viável, corporações multinacionais e os IDEs são mais propensos a ter um papel dominante; já quando viável, relacionamentos de curta distância são possíveis e IDEs tornam-se menos relevantes.

(8) Sob a perspectiva do emprego, Baldwin e Venables (2013) argumentam que os processos de outsourcing e offshoring de postos de trabalho espalharam-se das fábricas para os escritórios. Daudin, Rifflart e Danielle (2011) argumentam que a rede de produção em CGV tem sido baseada em uma nova divisão internacional do trabalho, diferente da tradicional divisão entre bens primários e manufaturados. 
O conceito "Made in Country $X$ " tornou-se obsoleto. Diferentemente de quando os economistas argumentavam sobre vantagens comparativas e especialização internacional em termos de produtos finais, não é mais a média da intensidade dos fatores produtivos do produto final o que determina a localização de sua produção, mas a intensidade dos fatores de cada componente (Arndt; Kierzkowski, 2001; Johnson, 2014; Los et al., 2015; Riad et al., 2011). Os bens finais são considerados "pacotes" de fatores produtivos de muitas nações (Baldwin, 2011). Nesse sentido, a forma como cada país especializa-se em estágios particulares de uma sequência do processo produtivo é frequentemente apresentada como especialização vertical ${ }^{9}$. A disponibilidade de matrizes insumo-produto globais tornou possível ampliar o conceito de especialização vertical inicialmente proposto e capturar diferentes características do comércio internacional ${ }^{10}$. Por outro lado, quando a especialização vertical estava limitada a poucos países, era possível utilizar dados brutos de comércio sem exagerar o conteúdo nacional das exportações (Hummels; Ishii; Yi, 2001; Johnson, 2014).

Da mesma forma, era possível representar o vazamento de demanda agregada sob a forma de importação de bens e serviços a partir dos valores dos bens finais sem minimizar o conteúdo de insumos importados. No entanto, as recentes transformações na relação entre produção e comércio impõem o aprimoramento dos métodos de medição utilizados. Normalmente, a análise do vazamento de demanda estabelece uma relação entre uma proxy da demanda por bens industriais e a produção industrial doméstica, indicando que quando a primeira supera o montante da última, há o vazamento da demanda agregada por meios da importação de bens e serviços. A próxima seção apresenta alguns indicadores tradicionalmente utilizados para mensurar a demanda doméstica por bens industriais, ressaltando a ótica do consumo aparente.

\section{0 tradicional retrato do vazamento de demanda para o exterior}

O recente cenário de desaceleração do crescimento econômico tem suscitado discussões a respeito de um crescente vazamento da demanda agregada da economia brasileira para o exterior, uma vez que haveria um descompasso entre (decrescente) produção industrial doméstica e (crescente) demanda doméstica. Os dados da Pesquisa Industrial Mensal de Produção Física (PIM-PF) revelam o mau desempenho da produção industrial no período recente. Após recuperar-se da

(9) Hummels, Ishii e Yi (2001) desenvolveram inicialmente o conceito de especialização vertical, cuja característica fundamental é a presença de insumos importados nas exportações de um país.

(10) Ver Amador e Mauro (2015); Daudin; Rifflart e Schweisguth (2011); Di Giovanni e Levchenko (2010); Hummels; Ishii e Yi (2001); Johnson e Noguera (2012); Los; Timmer e de Vries (2015); Stehrer (2013). 
acentuada queda em meio à crise internacional de 2008, a produção doméstica da indústria de transformação restabeleceu níveis semelhantes ao patamar pré-crise em 2010, permanecendo estagnada até 2013, para então apresentar vertiginosas quedas, reaproximando-se do seu pior desempenho no auge da crise de $2008^{11}$. Se, por um lado, não restam dúvidas quanto ao mau desempenho da produção industrial doméstica, por outro lado, não há consenso quanto aos seus fatores explicativos e quanto ao conseguinte vazamento de demanda. Parte dessa discordância pode ser entendida pela dificuldade em construir medidas que representem adequadamente o comportamento da demanda de bens e serviços.

Uma forma de entender o vazamento de demanda doméstica é a partir da diferença entre o quantum importado e o quantum exportado. No caso de um excesso de demanda doméstica, esse seria suprido por um crescimento superior das importações em relação às exportações, desconsiderando a variação de estoques. Ou seja, seria o equivalente a uma redução das exportações líquidas, dada a incapacidade da produção industrial doméstica atender a todo estímulo da demanda doméstica. Carvalho e Ribeiro (2015) mostram que, nos últimos anos, as exportações líquidas têm contribuído negativamente para o crescimento do Produto Interno Bruto (PIB), corroborando para o entendimento de que uma parcela da crescente demanda doméstica tem vazado para o exterior. No entanto, segundo os autores, a observação dos dados das Contas Nacionais Trimestrais (IBGE) não permite uma avaliação precisa do comportamento da demanda doméstica de bens industriais, uma vez que não há qualquer distinção entre o que é direcionado a bens e o que é direcionado a serviços, além do fato da variação das exportações líquidas incluir bens que não pertencem ao setor industrial, como os produtos agrícolas ${ }^{12}$.

Na literatura, a proxy de demanda doméstica mais utilizada é chamada de consumo aparente (CA). A partir da ideia de equilíbrio entre oferta e demanda, o CA representa a absorção interna a partir da produção industrial doméstica acrescida das importações e subtraída das exportações. O vazamento de demanda sob a forma de importação de bens e serviços representa um eventual excesso de demanda sobre a oferta que não foi atendido pela produção industrial doméstica. Ou seja, o vazamento de demanda para o exterior é a diferença entre demanda doméstica e produção industrial doméstica. Essa diferença, em períodos mais longos de tempo, levaria necessariamente ao crescimento das importações e/ou contração das

(11) Os dados para a indústria em geral são muito próximos dos da indústria de transformação, uma vez que a última representa algo em torno de $90 \%$ do valor total da produção da indústria geral.

(12) Outro indicador ainda muito utilizado como proxy de demanda por bens industriais é o índice de venda do varejo. No entanto, tal indicador mostra-se ainda mais limitado comparativamente ao construído a partir dos dados das Contas Nacionais Trimestrais do IBGE, uma vez que desconsidera a oferta e demanda por bens de capital, e não inclui as exportações industriais. Ver Serrano e Summa (2015). 
exportações, o que significa uma contração das exportações líquidas (ou "vazamento externo"), uma vez que a produção industrial é igual às exportações líquidas somadas à demanda doméstica (Carvalho; Ribeiro, 2015; Serrano; Summa, 2015). No entanto, no curto prazo, o excesso de demanda pode ser suprido pela variação de estoques, o que faz com que o CA seja impreciso como indicador de demanda doméstica, uma vez que o mesmo é baseado em dados de oferta. Ademais, por apresentar certa convergência no tempo, valendo-se da prerrogativa de que as variações de estoque são insuficientes para acomodar variações de demanda em períodos mais longos de tempo, o CA continua sendo muito utilizado na literatura.

Os Gráficos 1, 2 e 3 apresentam o comportamento da produção industrial doméstica e do consumo aparente da economia brasileira no período de 2000 a 2013 , indicando ainda a diferença entre ambos - o vazamento externo, para três categorias de uso: os bens de capital, os bens intermediários e os bens de consumo ${ }^{13}$.

\section{Gráfico 1}

Produção doméstica, consumo aparente e vazamento externo* de bens de capital, $2000-2013$

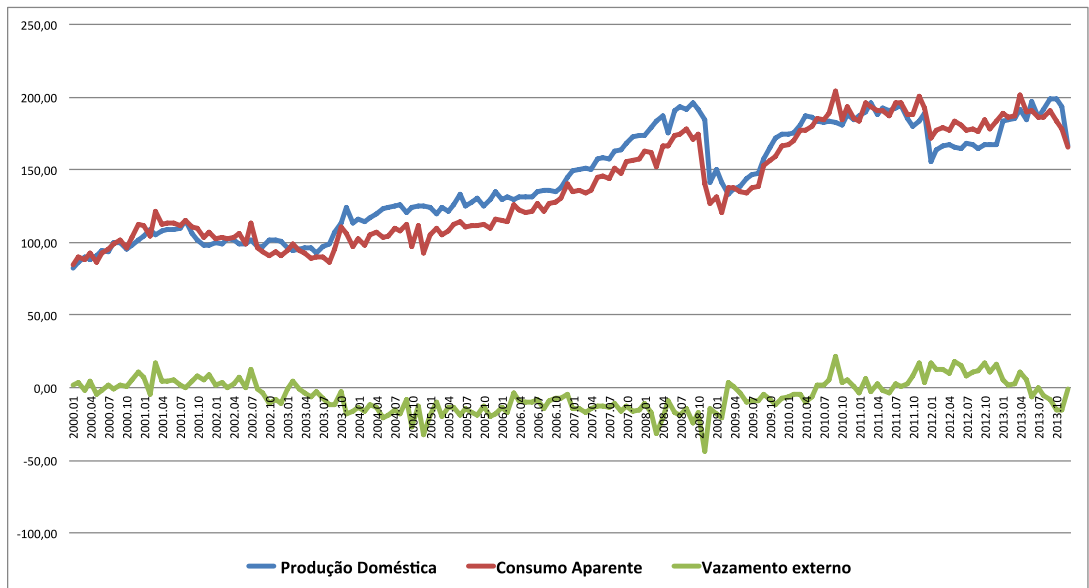

* O vazamento externo foi calculado tendo como base a diferença entre uma proxy da demanda doméstica (consumo aparente (IPEA)) e a produção industrial (medida pela PIM-PF (IBGE), quantum, dessazonalizado) (Índice = 100, em 2002).

Fonte: Elaboração própria, a partir dos dados do IPEA.

(13) Bastos et al. (2015) apresentam a relação entre produção e consumo aparente utilizando a subdivisão em categorias de uso. Nos gráficos aqui formulados buscou-se incorporar o comportamento do vazamento de demanda doméstica. 
Gráfico 2

Produção doméstica, consumo aparente e vazamento externo* de bens intermediários, 2000-2013

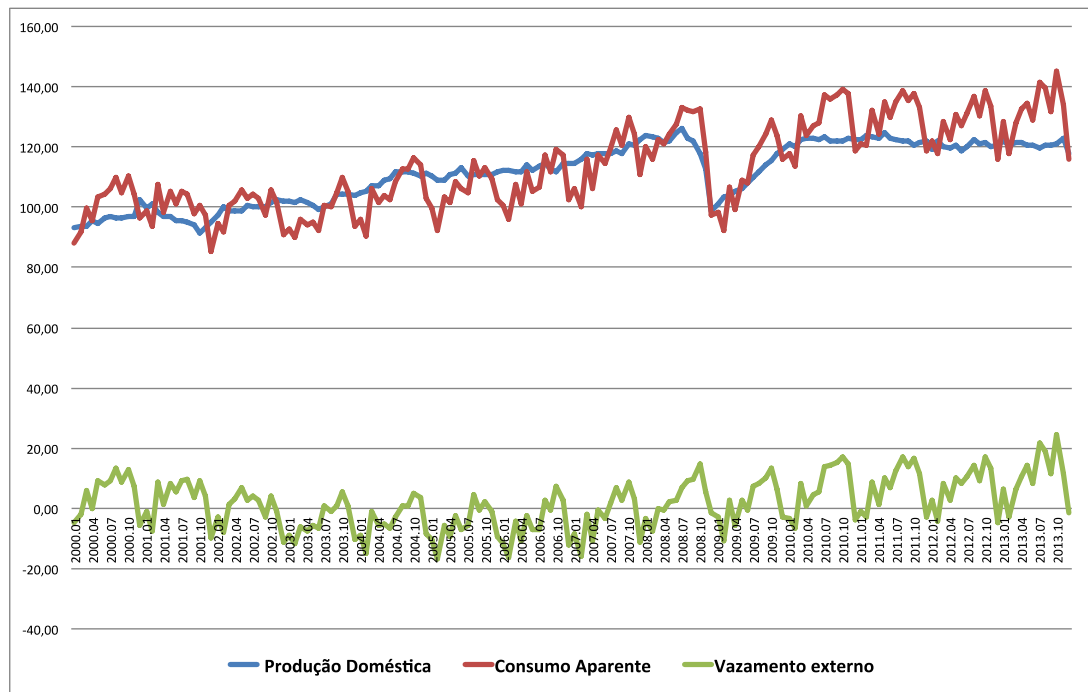

* O vazamento externo foi calculado tendo como base a diferença entre uma proxy da demanda doméstica (consumo aparente (IPEA)) e a produção industrial (medida pela PIM-PF (IBGE), quantum, dessazonalizado) (Índice = 100, em 2002).

Fonte: Elaboração própria, a partir dos dados do Ipea.

Gráfico 3

Produção doméstica, consumo aparente e vazamento externo* de bens de consumo, 2000-2013

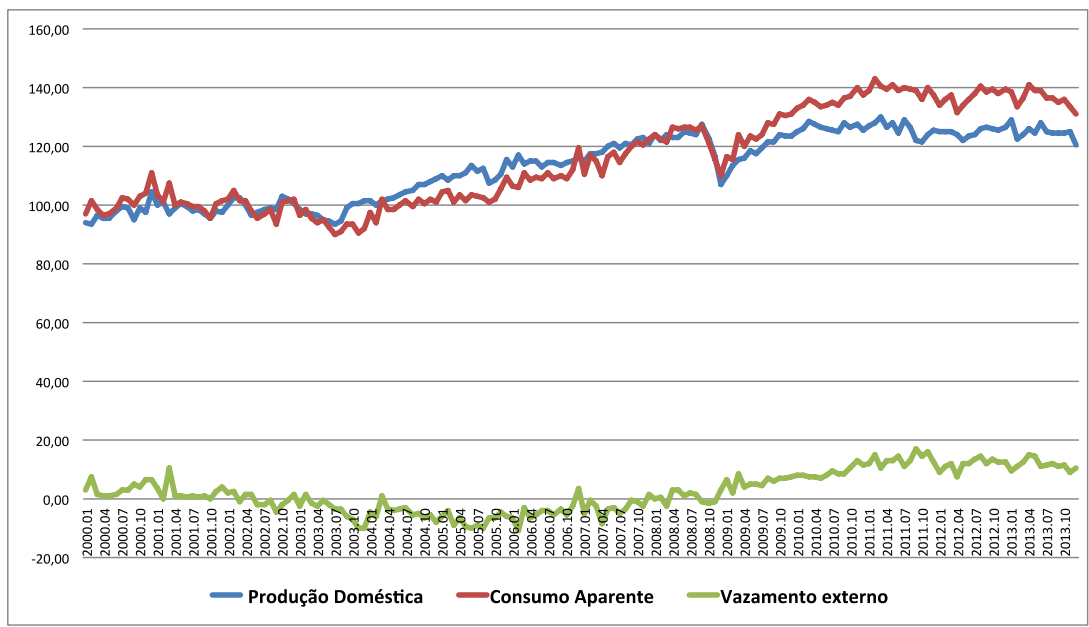

Fonte: Elaboração própria, a partir dos dados do IPEA.

* O vazamento externo foi calculado tendo como base a diferença entre uma proxy da demanda doméstica (consumo aparente (IPEA)) e a produção industrial (medida pela PIM-PF (IBGE), quantum, dessazonalizado) (Índice = 100, em 2002). 
Como é possível observar nos Gráficos 1, 2 e 3, há um padrão preocupante: i) no período anterior à crise de 2008 , a incapacidade da produção doméstica atender ao ritmo acelerado de absorção interna ainda encontrava-se em estado latente ${ }^{14}$; ii) após a crise de 2008, há um deslocamento ainda mais exacerbado entre produção industrial doméstica e o consumo aparente; iii) tal discrepância pós-crise mostrou-se ainda mais evidente no caso dos bens de consumo, ainda que seja possível afirmar que essa tendência mostrou-se enrijecida desde 2011. Portanto, a crise econômica que marcou o segundo semestre de 2008 parece ser o momento crucial de aprofundamento da tendência anterior ou, no caso dos bens de capital, de quebra de tendência. Ademais, a grande oscilação no caso dos bens intermediários exige maior qualificação a respeito dos seus fatores explicativos, especialmente tendo em vista a desaceleração do comércio mundial aliada às mudanças na produção mundial. Ainda assim, pode-se dizer que no período pós-crise o vazamento externo mostrou-se em um patamar superior ao do período pré-crise, corroborando para a hipótese de desadensamento da matriz produtiva brasileira.

Para avançar nessas qualificações, é preciso considerar as limitações do CA como proxy de demanda doméstica. Além de desconsiderar as variações de estoque, o CA não apresenta de forma clara a noção de que uma parcela cada vez maior das exportações é composta por insumos importados. Nesse sentido, a Confederação Nacional de Indústria (CNI) publica os coeficientes de penetração das importações e de insumos importados. No caso de uma análise desagregada em setores, a penetração das importações é avaliada a partir da relação entre o valor das importações do setor industrial analisado e o valor do consumo aparente do mesmo, indicando o percentual de demanda doméstica atendido pelas importações. A publicação da CNI utiliza os dados da Secex/MDIC e pode ser visualizada para a economia brasileira no Gráfico 4.

O Gráfico 4 indica uma tendência generalizada de aumento do percentual de demanda doméstica atendido pelas importações. Ou seja, as importações têm representado uma fração cada vez maior da oferta interna. Como já mencionado, este é um reflexo das mudanças vistas na produção e na sua relação com o comércio, dada a ampla difusão das cadeias globais de valor. Como já era esperado, os setores que apresentam processos produtivos mais passíveis de fragmentação são os que, inseridos na nova ordem produtiva internacional, apresentam os maiores coeficientes de penetração das importações.

(14) Neste caso, o comportamento dos bens de capital seria uma exceção, uma vez que diferente dos demais grandes ramos da indústria, a produção doméstica de bens de capital esteve acima da absorção interna de bens de capital grande parte do período pré-crise de 2008, mais especificamente ao longo do período de 2003-2008. 


\section{Gráfico 4}

Coeficiente de penetração das importações (\%), a preços constantes de 2007, anos: 2000 e variação em ponto percentual (2013 menos 2000)*

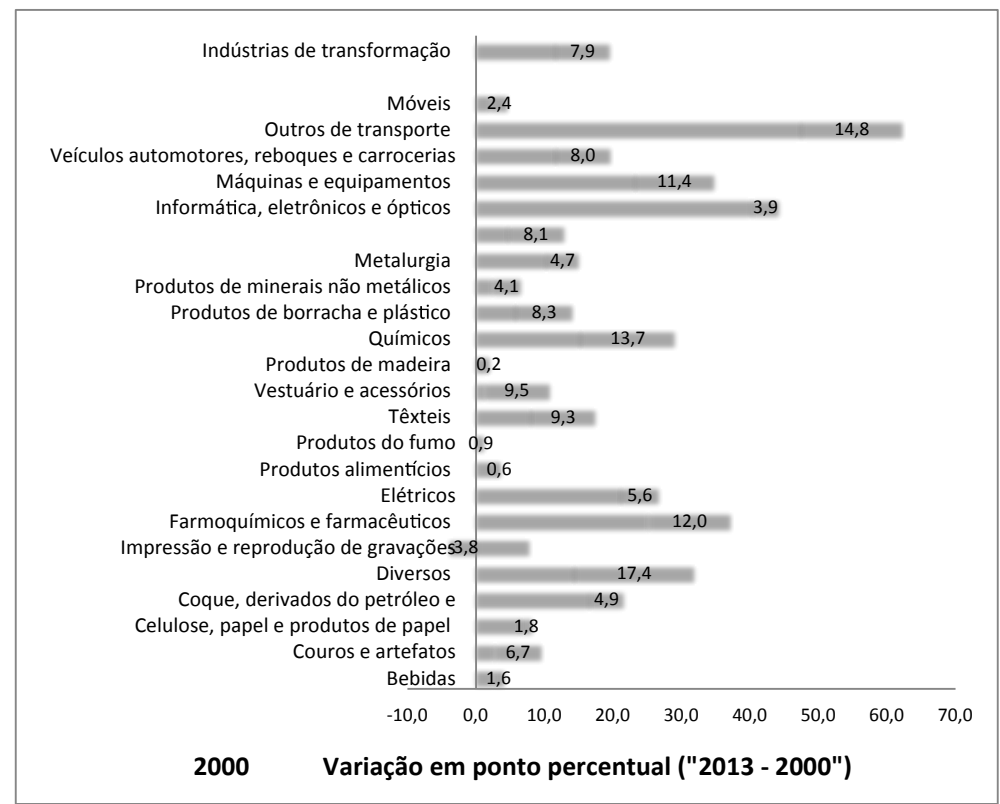

* A série tornou-se mensal a partir de janeiro de 2007. Coeficiente de penetração das importações, calculado sobre fluxos acumulados em quatro trimestres, a preços constantes de 2007. Para compatibilidade dos dados, foi utilizado o quarto trimestre de 2000 e de 2013.

Fonte: Elaboração própria, a partir dos dados da CNI.

Por sua vez, o coeficiente de insumos importados indica a participação dos insumos importados pelo setor industrial no valor de sua produção. Ainda que esse indicador contribua com uma noção geral a respeito da importância das importações como parcela dos insumos importados, justamente por operarem - tanto o coeficiente de penetração das importações, como o de insumos importados - em um nível amplo de agregação, tais índices não captam precisamente a interconectividade entre produção e comércio internacional. Com a competitividade internacional cada vez mais pautada em termos da intensidade dos fatores de cada componente do produto final, a agregação em setores econômicos tem se tornado uma forma insuficiente de avaliar a relação entre oferta e demanda doméstica. Além disso, os dados estão disponíveis apenas para as indústrias extrativas e de transformação, não havendo qualquer qualificação a respeito dos setores de serviços. A próxima seção busca contribuir com os métodos de análise de vazamento de demanda doméstica para o exterior a partir das matrizes insumo-produto da economia brasileira, incorporando considerações a respeito da variação de estoques na proxy da demanda doméstica. 


\section{Indicadores de vazamento externo a partir das matrizes insumo-produto}

Para identificar se houve vazamento de demanda doméstica para o exterior sob a forma de importação de bens e serviços, este estudo propõe construir coeficientes de penetração das importações e de insumos importados a partir das matrizes insumo-produto estimadas para a economia brasileira. Ainda que seja possível ampliar o grau de desagregação, visualizando a interação intrasetorial, para o objetivo deste estudo, caberá seguir o nível de desagregação compatível com o Sistema de Contas Nacionais. Propõe-se acrescentar evidências a respeito dos efeitos, diretos e indiretos, que um aumento na importação e produção de determinado setor econômico possuem sobre a importação e produção da matriz produtiva brasileira (multiplicadores de importação e de produção). Além disso, buscou-se aprofundar o entendimento a respeito da interconectividade que existe entre demanda total ${ }^{15}$ e importação, atentando para os efeitos que um estímulo de demanda possui sobre um possível aumento nas importações (multiplicador de vazamento de demanda). Para uma visão detalhada do método utilizado, as próximas subseções apresentam algumas considerações teóricas a respeito da análise empírica proposta.

\subsection{Coeficientes de penetração das importações e de insumos importados}

Os coeficientes de insumos importados e de penetração das importações foram obtidos a partir das matrizes de insumo-produto dos anos de 2000, 2008, 2009 e 2013 estimadas por Guilhoto e Sesso Filho (2005, 2010, 2016). Os valores da produção, consumo intermediário dos produtos importados, importações, insumos domésticos e os valores da demanda final foram obtidos em reais correntes. A análise encontra-se agrupada em 33 setores. O coeficiente de penetração das importações (CPI), calculado com base nas matrizes de recursos e usos e de importação é obtido da seguinte fórmula ${ }^{16}$ :

$$
C P I_{i}=\frac{V_{i}^{m}}{D D_{i}}
$$

onde,

$C P I_{i}=$ coeficiente de penetração de importações no setor industrial $i$;

$V_{i}^{m}=$ valor das importações do setor industrial $i$;

(15) Optou-se aqui por utilizar o conceito de demanda total, que inclui as exportações e variações de estoque, uma vez que, em um mundo com processos produtivos fragmentados e internacionalizados, grande parte dos acréscimos na importação ocorrem como resposta a estímulos da demanda externa, ou seja, para atender às exportações. Essa abordagem é complementar à apresentada cujo enfoque é a demanda doméstica.

(16) Os coeficientes e multiplicadores foram baseados na metodologia presente em Miller e Blair (2009). O coeficiente de penetração das importações (CPI) segue a mesma abordagem de Rocha (2011). 
$D D_{i}=$ demanda doméstica (consumo intermediário total + consumo (famílias, administração pública, ISFLSF $)+F B K F+$ variação de estoque $)^{17}$

Ou seja, o CPI indica a perda de capacidade da produção industrial doméstica para atender a um aumento de demanda doméstica.

O coeficiente de insumos importados $(\mathrm{CII})^{18}$, por sua vez, é obtido da seguinte fórmula tendo como base a matriz de recursos e usos dos anos em estudo:

$$
C I I_{i}=\frac{M_{i}}{V_{i}^{p}}
$$

onde,

$\mathrm{CII}_{i}=$ coeficiente de insumos importados;

$M_{i}=$ valor dos insumos importados do setor $i$;

$V_{i}^{p}=$ valor da produção do setor $i$;

Ou seja, o CII representa a parcela necessária de insumos importados em relação à produção do setor. Tal contribuição consiste em um avanço na caracterização do vazamento de demanda para o exterior pois considera as variações de estoques em sua proxy de demanda doméstica, além de valer-se do nível de desagregação proporcionado pelas matrizes insumo-produto.

\subsection{Multiplicadores de produção, importação e vazamento de demanda}

A partir dos coeficientes técnicos de produção diretos (da matriz diagonal básica de Leontief) e da matriz inversa de Leontief, é possível estimar para cada setor da economia o quanto é gerado direta e indiretamente de emprego, importações, impostos, salários, valor adicionado, entre outros, para cada unidade monetária produzida para a demanda final. Assim, para o multiplicador de importação:

$$
G I_{J}=\sum_{i=1}^{n} b_{i j} i_{i}
$$

onde, $G I_{J}$ é o impacto total, direto e indireto, sobre as importações (variável $i$ em questão); $b_{i j}$ é o ij-ésimo elemento da matriz inversa de Leontief; e $i_{i}$ é o coeficiente direto de importação para o setor $i$;

(17) A soma de cada item da demanda final separadamente permite que seja excluída da variável o valor do total da produção que foi exportado.

(18) A metodologia utilizada no cálculo do coeficiente de insumos importados (CII) difere da metodologia presente em Rocha (2011) e em Marconi e Rocha (2012), pois considera os coeficientes diretos de importação pelo setor e não o conjunto de efeitos diretos e indiretos (efeitos totais). Trata-se de uma metodologia complementar à proposta pelos autores, uma vez que aborda o montante direto importado pelo setor em determinado ano e não o possível impacto total no aumento das importações do referido setor por encadeamentos produtivos dado um choque na demanda final, mantida a tecnologia em uso. A escolha por esse método deveu-se à utilização no artigo do multiplicador de vazamento de demanda (MVD) como forma de contar os efeitos diretos e indiretos de importação de um estímulo de demanda. Ademais, a inovação do cálculo tanto do CPI quanto do CII reside na utilização das matrizes insumo-produto de 2000 a 2013. 
A divisão dos geradores pelo coeficiente direto de importação do setor $j$ gera o multiplicador de importação $\left(M I_{j}\right)$, que indica o quanto é gerado, direta e indiretamente, de importações em todos os setores que compõem a estrutura produtiva, dado um estímulo de importação em determinado setor (Guilhoto, 2011).

$$
M I_{j}=\frac{G I_{j}}{I_{j}}
$$

Os multiplicadores apresentam os efeitos diretos e indiretos para a economia, dado um estímulo de demanda em determinado setor. O multiplicador de produção $\left(M P_{J}\right)$, por sua vez, indica a variação na produção, para cada unidade monetária gasta no consumo final, sendo avaliados tanto os efeitos sobre o próprio setor, como o impacto que o setor pode ter em outros setores, a partir de diferentes canais de transmissão insumo-produto.

$$
M P_{J}=\sum_{i=1}^{n} b_{i j}
$$

Os multiplicadores de produção, de acordo com Miller e Blair (2009), se desdobram ainda em efeitos diretos e indiretos. Os efeitos diretos referem-se ao valor total que o setor $i$ produzirá para satisfazer o aumento na sua demanda final e ainda para atender à demanda de todos os demais setores. O efeito indireto, por outro lado, consiste no valor total da produção necessário, em todos os setores da economia, para satisfazer o aumento de uma unidade monetária na demanda final pelo produto do setor $i$.

Ampliando o retrato do vazamento de demanda doméstica, considerou-se a relação entre demanda total ${ }^{19}$ e importações. Para identificar se a estrutura de oferta foi capaz de acomodar internamente os estímulos de demanda, optou-se pela estimação de um multiplicador de vazamento de demanda $\left(M V D_{j}\right)$. Ao estimular a demanda total de um setor $j$, calculamos a variação no valor das importações de insumos do próprio setor $j$ (efeito direto) e a variação das importações dos demais setores (efeito indireto). Tal multiplicador aponta para a incapacidade da produção doméstica de insumos de atender a um estímulo na demanda total de determinado setor, compreendida como a somatória entre demanda por bens intermediários e finais.

O multiplicador foi calculado tendo como base os coeficientes de importação dos setores obtidos pelas matrizes de recursos e usos e a matriz inversa de Leontief. Assim, o vazamento de demanda total $M V D_{j}$ de um estímulo de demanda no setor $j$ é alcançado pela somatória da multiplicação entre o coeficiente de importação de cada setor e a variação de sua produção para cada unidade monetária gasta na demanda total do setor $j$.

(19) A demanda total inclui as exportações e variações de estoque. 


$$
M V D_{J}=\sum_{i=1}^{n} b_{i j} i_{i}
$$

Ou seja, trata-se do produto entre o vetor linha $I_{j}$ de coeficientes de importação e a matriz inversa de Leontief ${ }^{20}$.

\section{Análise empírica para a economia brasileira}

O retrato dos coeficientes de insumos importados e de penetração das importações, vide Tabela 1, apresenta uma tendência geral de aumento da participação das importações, tanto de insumos importados quanto de bens finais, na economia brasileira.

\section{Tabela 1}

Variação dos coeficientes de insumos importados e de penetração das importações (2013-2009/2008-2000) (ponto percentual)

\begin{tabular}{|c|c|c|c|c|}
\hline \multirow[t]{2}{*}{ Setor de atividade } & \multicolumn{2}{|c|}{$\begin{array}{l}\text { Coef. de Insumos } \\
\text { Importados }\end{array}$} & \multicolumn{2}{|c|}{$\begin{array}{l}\text { Coef. de Penetração } \\
\text { das Importações }\end{array}$} \\
\hline & 2008-2000 & 2013-2009 & 2008-2000 & 2013-2009 \\
\hline Agropecuária & 0,02 & 0,01 & $-0,01$ & 0,01 \\
\hline Petróleo e gás natural & 0,00 & 0,00 & $-0,01$ & $-0,03$ \\
\hline Extrativa mineral & $-0,01$ & 0,00 & 0,28 & $-0,19$ \\
\hline Alimentos e bebidas & $-0,01$ & 0,01 & $-0,01$ & 0,02 \\
\hline Produtos do fumo & $-0,01$ & 0,01 & $-0,06$ & $-0,06$ \\
\hline Têxteis & 0,00 & 0,03 & 0,03 & 0,08 \\
\hline Artigos de vestuário & 0,02 & 0,02 & 0,02 & 0,11 \\
\hline Artefatos de couro e calçados & 0,00 & 0,01 & 0,01 & 0,03 \\
\hline Produtos de madeira - exclusive móveis & 0,00 & 0,01 & 0,00 & 0,00 \\
\hline Celulose, papel e gráfica & 0,00 & 0,03 & $-0,01$ & 0,02 \\
\hline Refino de petróleo e coque & 0,04 & 0,07 & 0,05 & 0,06 \\
\hline Fabricação de biocombustíveis & 0,00 & 0,01 & 0,00 & 0,01 \\
\hline Fabricação de produtos químicos & 0,04 & 0,12 & 0,05 & 0,20 \\
\hline Fabricação de produtos farmoquímicos & 0,01 & 0,02 & 0,05 & 0,14 \\
\hline Fabricação de defensivos e químicos diversos & 0,01 & 0,08 & 0,00 & 0,10 \\
\hline Artigos de borracha e plástico & 0,00 & 0,01 & 0,03 & 0,04 \\
\hline Fabricação de produtos minerais não-metálicos & 0,02 & 0,00 & 0,01 & 0,03 \\
\hline Metalurgia e siderurgia & 0,01 & 0,01 & 0,02 & 0,04 \\
\hline Fabricação de equipamentos de informática, produtos eletrônicos e ópticos & 0,01 & 0,10 & 0,11 & 0,05 \\
\hline Máquinas e equipamentos eletrônicos e mecânicos, inclusive manutenção e reparos & 0,00 & 0,05 & $-0,07$ & $-0,17$ \\
\hline Fabricação de móveis e indústrias diversas & 0,00 & 0,00 & 0,01 & 0,12 \\
\hline Fabricação de automóveis, caminhões e ônibus, exceto peças & $-0,01$ & 0,04 & $-0,02$ & 0,03 \\
\hline Fabricação de peças e acessórios para veículos automotores & 0,00 & 0,03 & $-0,09$ & 0,18 \\
\hline Fabricação de outros equipamentos de transporte & $-0,06$ & 0,02 & $-0,52$ & 4,14 \\
\hline Eletricidade e gás, água, esgoto e limpeza urbana & 0,01 & 0,02 & $-0,01$ & 0,00 \\
\hline Construção & 0,00 & 0,01 & 0,00 & 0,00 \\
\hline Comércio e serviços de reparação & 0,00 & 0,00 & 0,00 & 0,00 \\
\hline Transporte, armazenagem e correio & 0,01 & 0,02 & $-0,01$ & 0,01 \\
\hline Serviços de informação & 0,00 & 0,01 & 0,00 & 0,02 \\
\hline Intermediação financeira e seguros & 0,00 & 0,01 & 0,00 & 0,02 \\
\hline Serviços prestados às empresas & 0,00 & 0,01 & 0,00 & 0,04 \\
\hline Serviços prestados às famílias & 0,00 & 0,01 & 0,02 & $-0,02$ \\
\hline Serviços do governo & 0,00 & 0,00 & 0,00 & 0,00 \\
\hline
\end{tabular}

Fonte: Elaboração própria, a partir dos dados de Guilhoto e Sesso Filho (2013).

O coeficiente de insumos importados apresenta uma tendência ainda mais pujante no período pós-crise de 2008, mostrando uma crescente participação dos insumos importados como parcela do valor da produção do setor. A variação para o período de 2013-2009 foi positiva em todos os 33 setores analisados, o que significa que houve aumento dos insumos importados em relação ao valor da produção

(20) O multiplicador de vazamento de importação trata-se do gerador $G I_{J}$ obtido para o cálculo do multiplicador de importação. 
doméstica em toda a matriz produtiva brasileira. Os setores que inverteram a tendência observada no período anterior à crise, ou seja, passaram a depender ainda mais de insumos importados dado o valor da produção do setor foram, no setor primário: apenas a extrativa mineral; na indústria de transformação: alimentos e bebidas; produtos do fumo; artefatos de couro e calçados; fabricação de biocombustíveis; de automóveis, caminhões e ônibus; de peças e acessórios para veículos automotores; de equipamentos de transporte; no setor de serviços: comércio e serviços de reparação e intermediação financeira e seguros. Este indicador reforça o caráter estrutural da mudança na relação entre produção e comércio internacional. Ainda assim deve-se lembrar que o coeficiente de insumos importados e de penetração das importações podem ser diretamente afetados (aumentam) pela desvalorização cambial do real que prevaleceu no período pós-crise, ainda que seja preciso analisar as deficiências estruturais de cada setor econômico, uma vez que mesmo em momentos de valorização cambial do real, não se pode dizer que ocorreu uma massiva substituição dessas importações por bens produzidos domesticamente ${ }^{21}$.

Ao analisar o coeficiente de penetração das importações, os setores que apresentaram maior participação do valor das importações em relação à demanda doméstica no período pós-crise estão concentrados na indústria de transformação. Dos setores que passaram a depender menos das importações como fração da demanda doméstica no período pós crise, apenas petróleo e gás natural; produtos do fumo; Máquinas e equipamentos eletrônicos e mecânicos, inclusive manutenção e reparos; e Eletricidade e gás, água, esgoto e limpeza urbana perpetuaram uma tendência já cristalizada anteriormente à crise. Ou seja, já vinham assistindo à queda da participação das importações de bens finais dada a demanda doméstica. Destacase que em quatro setores houve uma redução do coeficiente de penetração das importações acompanhada de elevação do coeficiente de insumos importados, o que significa dizer que não houve correspondência em termos de crescimento da importação de insumos e um possível crescimento da importação em relação à demanda doméstica. Portanto, nesses setores, um aumento na demanda doméstica não foi acomodado por um aumento nas importações, ainda que haja evidências de que tal estímulo possa ter desencadeado um aumento na importação de insumos, refletindo processos produtivos em cadeias globais de valor, fragmentados e dispersos internacionalmente.

Para avançar na caracterização do vazamento de demanda da economia brasileira, a Tabela 2 apresenta a variação dos multiplicadores de importação para o período pré e pós-crise.

(21) Para uma análise que considera elementos estruturalistas, ver (Santos et al., 2015). 
Tabela 2

Multiplicadores de importação e de produção (2013-2009/2008-2000) (ponto percentual)

\begin{tabular}{|c|c|c|c|c|}
\hline \multirow[t]{2}{*}{ Setor de atividade } & \multicolumn{2}{|c|}{$\begin{array}{l}\text { Multiplicador de } \\
\text { Importação }\end{array}$} & \multicolumn{2}{|c|}{ Multiplicador de Produção } \\
\hline & $2008-2000$ & 2013-2009 & $2008-2000$ & 2013-2009 \\
\hline Agropecuária & $-0,10$ & 0,25 & 0,09 & $-0,08$ \\
\hline Petróleo e gás natural & 0,08 & $-0,21$ & $-0,01$ & $-0,48$ \\
\hline Extrativa mineral & 0,11 & 0,09 & $-0,13$ & $-0,24$ \\
\hline Alimentose bebidas & 1,28 & $-0,01$ & 0,11 & $-0,08$ \\
\hline Produtos do fumo & 1,48 & $-0,43$ & 0,23 & $-0,22$ \\
\hline Têxteis & 0,03 & 0,13 & $-0,05$ & 0,08 \\
\hline Artigos de vestuário & $-0,47$ & $-0,04$ & 0,00 & $-0,02$ \\
\hline Artefatos de couro e calçados & 0,04 & 0,12 & $-0,09$ & $-0,08$ \\
\hline Produtos de madeira - exclusive móveis & 0,24 & $-0,11$ & 0,12 & $-0,04$ \\
\hline Celulose, papel e gráfica & 0,13 & 0,06 & 0,02 & 0,10 \\
\hline Refino de petróleo e coque & $-0,04$ & 0,13 & 0,09 & 0,26 \\
\hline Fabricação de biocombustiveis & 2,18 & $-1,39$ & $-0,07$ & 0,20 \\
\hline Fabricação de produtos químicos & $-0,11$ & $-0,07$ & $-0,05$ & $-0,08$ \\
\hline Fabricação de produtos farmoquímicos & 0,08 & 0,06 & 0,07 & 0,03 \\
\hline Fabricação de defensivos e químicos diversos & 0,08 & $-0,08$ & $-0,02$ & $-0,06$ \\
\hline Artigos de borracha e plástico & 0,10 & 0,26 & $-0,06$ & 0,04 \\
\hline Fabricação de produtos minerais não-metálicos & $-0,05$ & 0,38 & 0,03 & 0,05 \\
\hline Metalurgia e siderurgia & $-0,02$ & 0,16 & 0,01 & 0,11 \\
\hline Fabricação de equipamentos de informática, produtos eletrônicos e ópticos & $-0,01$ & $-0,09$ & 0,01 & $-0,14$ \\
\hline Máquinas e equipamentos eletrônicos e mecânicos, inclusive manutenção e reparos & 0,12 & $-0,21$ & 0,04 & $-0,10$ \\
\hline Fabricação de móveis e indústrias diversas & 0,09 & 0,08 & 0,00 & $-0,08$ \\
\hline Fabricação de automóveis, caminhōes e ônibus, exceto peças & 0,26 & $-0,26$ & 0,13 & $-0,22$ \\
\hline Fabricação de peças e acessórios para veículos automotores & 0,21 & $-0,13$ & 0,10 & $-0,09$ \\
\hline Fabricação de outros equipamentos de transporte & 0,26 & $-0,10$ & 0,26 & $-0,18$ \\
\hline Eletricidade e gás, água, esgoto e limpeza urbana & $-0,01$ & 0,14 & 0,04 & 0,21 \\
\hline Construçāo & 0,08 & $-0,02$ & $-0,04$ & 0,06 \\
\hline Comércio e serviços de reparação & 0,28 & 0,38 & $-0,01$ & 0,11 \\
\hline Transporte, armazenagem e correio & 0,23 & 0,00 & 0,08 & 0,07 \\
\hline Serviços de informação & 0,11 & $-0,09$ & 0,01 & $-0,04$ \\
\hline Intermediação financeira e seguros & $-0,05$ & 0,06 & $-0,16$ & 0,06 \\
\hline Serviços prestados às empresas & 0,07 & $-0,27$ & $-0,04$ & $-0,08$ \\
\hline Serviços prestados às famílias & 0,06 & $-0,28$ & 0,04 & $-0,07$ \\
\hline Serviços do governo & 0,05 & $-0,04$ & 0,00 & $-0,10$ \\
\hline
\end{tabular}

Fonte: Elaboração própria a partir dos dados de Guilhoto e Sesso Filho (2013).

O multiplicador de importação com sinal negativo significa que, para o período analisado, há uma tendência decrescente em termos do montante de importação gerado, direta e indiretamente, em todos os setores que compõem a estrutura produtiva, dado um aumento de importação deste setor. Considerando-se os diferentes canais de transmissão insumo-produto, há um menor vazamento de demanda sob a forma de importação de bens e serviços na economia brasileira, dado um aumento focalizado de importação em um determinado setor. Em outras palavras, uma maior importação em um setor não necessariamente significará maior importação nos demais setores que compõem a matriz produtiva brasileira.

A Tabela 2 apresenta uma tendência generalizada de menor efeito multiplicador da importação para o período pós-crise comparativamente ao período anterior à crise de 2008. Ou seja, pode-se dizer que houve um aumento no número de setores que passaram a estimular menos as importações de toda matriz produtiva. Essa tendência mostrou-se ainda mais evidente no caso da indústria de transformação. Dessa forma, um aumento nas importações de um setor específico não fez com que a demanda interindustrial fosse acomodada cada vez mais a partir da produção do setor externo. 
Por outro lado, o multiplicador de produção com sinal negativo (22 setores) mostra que, para o período pós-crise, a tendência é que um aumento na produção de um setor específico tenha como contrapartida estímulos, direta e indiretamente, cada vez menores à produção dos demais setores. Essa tendência é ainda mais evidente na indústria de transformação (13 setores). Assim, menores multiplicadores de produção indicam que um aumento na produção de um setor apresenta uma capacidade menor de estimular a produção dos demais setores que compõem a matriz. Dessa forma, pode-se dizer que se, por um lado, não haverá maior vazamento de demanda para o exterior, por outro não haverá maior estímulo à produção doméstica. Nem tanto ao céu nem tanto ao inferno. Os multiplicadores mostram, por fim, justamente a quebra dos elos das cadeias produtivas brasileiras, vista sob a perspectiva da produção e da importação.

Por fim, o estudo propõe-se a combinar estímulos de demanda com variações nas importações, ampliando o conceito de demanda utilizado para o de demanda total (incorporando variações de estoque e exportações).

Tabela 3

Multiplicador de vazamento de demanda, 2000, 2008, 2009, 2013

(2013-2009; 2008-2000, ponto percentual)

\begin{tabular}{|c|c|c|c|c|c|c|}
\hline \multirow{2}{*}{ Setor de atividade } & \multicolumn{6}{|c|}{ Multiplicador de vazamento de demanda } \\
\hline & 2000 & 2008 & 2009 & 2010 & $2008-2000$ & 2013-2009 \\
\hline Agropecuária & 0,07 & 0,11 & 0,08 & 0,11 & 0,03 & 0,03 \\
\hline Petróleo e gás natural & 0,08 & 0,08 & 0,10 & 0,09 & 0,00 & $-0,01$ \\
\hline Extrativa mineral & 0,10 & 0,10 & 0,09 & 0,10 & $-0,01$ & 0,00 \\
\hline Alimentos e bebidas & 0,10 & 0,10 & 0,08 & 0,11 & 0,01 & 0,03 \\
\hline Produtos do fumo & 0,08 & 0,09 & 0,08 & 0,09 & 0,02 & 0,01 \\
\hline Têxteis & 0,13 & 0,13 & 0,12 & 0,18 & 0,00 & 0,06 \\
\hline Artigos de vestuário & 0,09 & 0,10 & 0,09 & 0,12 & 0,02 & 0,03 \\
\hline Artefatos de couro e calçados & 0,14 & 0,13 & 0,11 & 0,13 & 0,00 & 0,02 \\
\hline Produtos de madeira - exclusive móveis & 0,07 & 0,09 & 0,06 & 0,10 & 0,02 & 0,03 \\
\hline Celulose, papel e gráfica & 0,10 & 0,12 & 0,09 & 0,16 & 0,01 & 0,06 \\
\hline Refino de petróleo e coque & 0,24 & 0,29 & 0,20 & 0,34 & 0,05 & 0,14 \\
\hline Fabricação de biocombustiveis & 0,06 & 0,07 & 0,06 & 0,11 & 0,01 & 0,05 \\
\hline Fabricação de produtos químicos & 0,25 & 0,29 & 0,22 & 0,39 & 0,05 & 0,17 \\
\hline Fabricação de produtos farmoquímicos & 0,11 & 0,13 & 0,11 & 0,16 & 0,02 & 0,05 \\
\hline Fabricação de defensivos e químicos diversos & 0,20 & 0,22 & 0,18 & 0,30 & 0,02 & 0,13 \\
\hline Artigos de borracha e plástico & 0,22 & 0,23 & 0,19 & 0,24 & 0,01 & 0,05 \\
\hline Fabricação de produtos minerais não-metálicos & 0,11 & 0,14 & 0,11 & 0,14 & 0,03 & 0,03 \\
\hline Metalurgia e siderurgia & 0,15 & 0,17 & 0,14 & 0,17 & 0,02 & 0,03 \\
\hline Fabricação de equipamentos de informática, produtos eletrônicos e ópticos & 0,23 & 0,24 & 0,21 & 0,33 & 0,01 & 0,12 \\
\hline Máquinas e equipamentos eletrônicos e mecânicos, inclusive manutenção e reparos & 0,16 & 0,17 & 0,14 & 0,20 & 0,01 & 0,06 \\
\hline Fabricação de móveis e indústrias diversas & 0,11 & 0,12 & 0,10 & 0,11 & 0,01 & 0,01 \\
\hline Fabricação de automóveis, caminhões e ônibus, exceto peças & 0,18 & 0,20 & 0,17 & 0,22 & 0,01 & 0,05 \\
\hline Fabricação de peças e acessórios para veículos automotores & 0,16 & 0,17 & 0,15 & 0,19 & 0,01 & 0,04 \\
\hline Fabricação de outros equipamentos de transporte & 0,30 & 0,26 & 0,22 & 0,24 & $-0,03$ & 0,01 \\
\hline Eletricidade e gás, água, esgoto e limpeza urbana & 0,06 & 0,08 & 0,06 & 0,11 & 0,02 & 0,05 \\
\hline Construção & 0,08 & 0,09 & 0,07 & 0,10 & 0,01 & 0,03 \\
\hline Comércio e serviços de reparação & 0,04 & 0,04 & 0,04 & 0,05 & 0,00 & 0,02 \\
\hline Transporte, armazenagem e correio & 0,08 & 0,11 & 0,08 & 0,13 & 0,02 & 0,05 \\
\hline Serviços de informação & 0,05 & 0,06 & 0,06 & 0,07 & 0,01 & 0,01 \\
\hline Intermediação financeira e seguros & 0,04 & 0,03 & 0,03 & 0,04 & $-0,01$ & 0,01 \\
\hline Serviços prestados às empresas & 0,04 & 0,05 & 0,04 & 0,05 & 0,00 & 0,01 \\
\hline Serviços prestados às familias & 0,03 & 0,04 & 0,03 & 0,04 & 0,01 & 0,01 \\
\hline Serviços do governo & 0,03 & 0,04 & 0,03 & 0,04 & 0,00 & 0,00 \\
\hline
\end{tabular}

Fonte: Elaboração própria a partir dos dados de Guilhoto e Sesso Filho (2013).

O multiplicador de vazamento de demanda $\left(M V D_{j}\right)$, vide Tabela 3, apresentou algumas regularidades: i) o período pós-crise marca a deterioração 
aprofundada da capacidade da estrutura produtiva doméstica em acomodar internamente estímulos da demanda total de um setor específico; ii) o auge da crise de 2008, delimitado temporalmente pela passagem de 2008 para 2009, representa uma queda generalizada no patamar de vazamento de demanda, com exceção de 3 setores de serviços que passam marginais à crise e do setor de petróleo e gás natural que apresenta um aumento no índice; ii) a indústria de transformação apresentou os maiores índices de $M V D_{j}$, em absoluto, para todo período analisado; assim como a maior tendência de crescimento no período pós-crise; iii) o aglomerado de serviços foi o que menos colaborou para que um estímulo de demanda - doméstica e externa - nos setores tomasse a forma de um amento nas importações da matriz produtiva brasileira.

\section{Considerações finais}

Este trabalho buscou realizar uma abordagem um pouco diferente da convencionalmente utilizada para retratar o vazamento de demanda para o exterior. $\mathrm{O}$ artigo utilizou, além dos indicadores usuais, a abordagem de insumo-produto para avaliar e qualificar sua ocorrência na economia brasileira, setorialmente e no tempo. Nesse sentido, buscou-se aprimorar sua caracterização ao utilizar uma proxy de demanda doméstica que se mostrou mais coerente em relação às profundas mudanças na dinâmica entre produção industrial e comércio internacional, incorporando ainda as críticas direcionadas ao indicador usual (consumo aparente) ao considerar as variações de estoque nos setores analisados.

Pode-se extrair algumas observações no que se refere ao fenômeno do vazamento de demanda na economia brasileira ao longo do período de 2000 a 2013. A primeira é que a forma como a produção industrial doméstica relaciona-se com o setor externo agravou-se consideravelmente após a crise econômica de 2008. A crise de 2008 é considerada um marco para diversos estudiosos no âmbito da literatura de cadeias globais de valor justamente por ter sido a primeira crise econômica com efeitos amplamente difundidos desde a globalização da produção, i.e. o uso expandido das GVCs (Milberg; Winkler, 2010). Nesse sentido, ao mesmo tempo em que o comércio internacional é considerado uma das maiores "vítimas" da crise mundial, as CGVs apresentaram-se como um importante canal através do qual a crise foi transmitida entre os países. No entanto, a forma como cada país especializa-se em estágios particulares de uma sequência do processo produtivo é um fator relevante quando se analisa a transmissão de choques externos.

Os indicadores tradicionais apontam para o aprofundamento da diferença entre produção industrial doméstica e demanda doméstica no período pós-crise. A partir do segundo semestre de 2008, todas as categorias de uso analisadas - bens de capital, bens de consumo e bens intermediários - apresentaram um patamar de vazamento externo superior ao do período pré-crise, especialmente no caso dos bens de consumo. A recente contração do comércio mundial parece ter implicações 
profundas na economia brasileira, ainda mais quando se considera a deterioração da balança comercial no período analisado.

O comércio bilateral Brasil-China sintetiza a fragilidade da inserção comercial brasileira. O principal parceiro comercial brasileiro diversificou e aumentou o conteúdo tecnológico da sua cesta de bens transacionada, ao passo que as exportações brasileiras para a China continuaram profetizando a sina das commodities. Ou seja, enquanto a economia chinesa passou a ocupar posições nas CGVs associadas a atividades de maior valor adicionado, diversificando sua pauta de exportações e avançando no processo de economic upgrading, o Brasil permaneceu nas etapas iniciais das CGVs, mais especificamente ofertando bens intensivos em recursos naturais. Não apenas estamos mais suscetíveis às estratégias chinesas de crescimento econômico, dado o protagonismo chinês no fronte de parceiros comerciais, como estamos mais vulneráveis às oscilações de preços das commodities que, por sua vez, não têm favorecido o perfil exportador brasileiro no período pós-crise. No entanto, a diferença entre o quantum importado e o quantum exportado esconde elementos estruturais associados às crescentes exportações líquidas negativas que vão além dos movimentos de valorização/desvalorização cambial do real. $\mathrm{Na}$ busca por fatores explicativos, este estudo ressaltou o papel das recentes transformações na relação entre produção industrial e comércio internacional. Em um cenário de crescente especialização vertical, no qual cada vez mais importa-se para exportar, não restam dúvidas que a decrescente produção industrial doméstica, ainda que isso não signifique menor rentabilidade (Bastos et al., 2015), abriu espaço para que a produção externa acomodasse a crescente demanda doméstica. E é preciso frisar que ao observar a pauta de importações sinobrasileira, vê-se a presença marcante de setores cuja produção é passível de fragmentação e internacionalização. Nesse sentido, ainda que a emergência da especialização vertical possa representar uma oportunidade para diversos países em desenvolvimento explorarem suas capacidades produtivas em nichos mais especializados e se beneficiarem da integração comercial a partir das exportações, é preciso avaliar os riscos associados a tal participação nas CGVs sem ter como contrapartida um movimento dinâmico em direção a atividades de maior valor adicionado.

A análise dos coeficientes de insumos importados e de penetração das importações (também a partir do método tradicional) atestam para uma tendência geral de aumento da participação das importações na economia brasileira, tanto de insumos quanto de bens finais. A participação dos insumos importados como fração do valor da produção industrial doméstica aumentou no período pós-crise para todos os setores analisados, ainda que o cenário seja de contração do comércio internacional. Já as importações como fração da demanda doméstica, considerando as variações de estoque, foram ainda mais marcantes na indústria de transformação. 
Outro indicador utilizado para caracterizar a dinâmica de vazamento externo, incorporados os diferentes canais de transmissão insumo-produto, é o multiplicador de importação. Os estímulos gerados por um aumento na importação de um setor específico não se propagaram pela matriz produtiva brasileira com mais força no período pós-crise. Também não se pode dizer que um aumento na produção de um setor gerou maiores efeitos, diretos e indiretos, sobre a produção dos demais setores. No entanto, quando observada a relação existente entre estímulos de demanda total, acrescentando os estímulos de demanda externa e importações do setor estimulado e de todos os demais que compõem a matriz produtiva doméstica, observa-se uma profunda deterioração na capacidade produtiva doméstica de acomodar acréscimos de demanda total, especialmente nos setores que compõem a indústria de transformação. Tais indicadores atestam para o esgarçamento do tecido industrial brasileiro, que em meio a um processo competitivo cada vez mais pautado na especialização intra-produto, vê na quebra dos elos internos entre as etapas das cadeias de valor e no desadensamento da matriz produtiva brasileira uma forma de viver à sombra de si mesmo. No campo da formulação de políticas econômicas para recuperar o ritmo de crescimento econômico, é interessante perceber que há um grande risco de acabar por desperdiçar estímulos de demanda tão caros à economia brasileira.

\section{Referências bibliográficas}

AMADOR, J.; MAURO, F. DI. Introduction. In: AMADOR, J.; MAURO, F. DI (Org.). The age of global value chains: maps and policy issues. London: CEPR Press, 2015. p. 13-23.

ARNDT, S.; KIERZKOWSKI, H. Fragmentation: new production patterns in the world economy. CMC Faculty Books, 2001.

ATHUKORALA, P. Product fragmentation and trade patterns in east Asia. Asian Economic Papers, v. 4, p. 1-27, 2005.

BACKER, K. de; MIROUDOT, S. Mapping global value chains. OECD Trade Policy Papers, OECD Publishing, v. 159, p. 1-46, 2013.

BALDWIN, R. Globalisation: the great unbundling(s). Economic Council of Finland, v. 20, Sept. p. 51, 2006.

BALDWIN, R. Trade and industrialization after globalization's 2nd unbundling: how building and joining a supply chain are different and why it matters. p. 1-38, 2011.

BALDWIN, R.; VENABLES, A. J. Spiders and snakes: offshoring and agglomeration in the global economy. Journal of International Economics, v. 90, n. 2, p. 245-254, 2013. 
BASTOS, C. P. et al. Rentabilidade, investimento e produtividade na indústria de transformação brasileira: 2000-2009. In: NEGRI, F. de; CAVALCANTE, L. R. (Org.). Produtividade no Brasil: desempenho e determinantes. Brasília: Ipea, ABDI, 2015. v. 2. p. 209-254.

BRESSER-PEREIRA, L. C. The dutch disease and its neutralization: a Ricardian approach. Revista de Economia Política, v. 28, n. 1, p. 47-71, 2008.

CARVALHO, L. M. de; RIBEIRO, F. J. da S. P. Indicadores de consumo aparente de bens industriais: metodologia e resultados. Rio de Janeiro: [s.n.], 2015. (Texto para Discussão).

CATTANEO, O. et al. Joining, upgrading and being competitive in global value chains: a strategic framework. [S.l: s.n.], 2013. (Policy Research Working Paper, n. 6406).

DAUDIN, G.; RIFFLART, C.; DANIELLE, S. Who produces for whom in the world economy? Canadian Journal of Economics, v. 44, n. 4, p. 1403-1437, 2011.

DI GIOVANNI, J.; LEVCHENKO, A. A. Putting the parts together: trade, vertical linkages, and business cycle comovement. American Economic Journal: Macroeconomics, v. 2, n. 2, p. 95-124, 2010.

DIXON, R.; THIRLWALL, A. P. A model of regional growth-rate differences on Kaldorian lines. Oxford Economic Papers, v. 27, n. 2, p. 201-214, 1975.

FURTADO, C. Desenvolvimento e subdesenvolvimento. [S.1.]: Univ of California Press, 1964.

FURTADO, C. Teoria e política do desenvolvimento econômico. São Paulo: [s.n.], 1967.

GUILHOTO, J. J. M.; SESSO FILHO, U. A. Estimação da matriz insumo-produto a partir de dados preliminares das contas nacionais. Economia Aplicada, v. 9, n. 2, p. 277-299, 2005.

GUILHOTO, J. J. M.; SESSO FILHO, U. A. Estimação da matriz insumo-produto utilizando dados preliminares das contas nacionais: aplicação e análise de indicadores econômicos para o Brasil em 2005. Economia \& Tecnologia, v. 23, n. 6, p. 53-62, 2010.

GUILHOTO, J. J. M.; SESSO FILHO, U. A. Sistema de Matrizes de InsumoProduto, Brasil (1995-2013). Disponível em: http://www.usp.br/nereus/?dados= sistema-de-matrizes-de-insumo-produto-brasil-1995-2013. Acesso em: 4 fev. 2016. 
HOROWITZ, J.; RIKER, D. Measuring shifts in Brazil's trade using international input-output tables. Journal of International Commerce and Economics, p. 1-13, Apr. 2014.

HUMMELS, D.; ISHII, J.; YI, K.-M. The nature and growth of vertical specialisation in world trade. Journal of International Economics, v. 54, n. 1, p. 7596, 2001.

INTERNATIONAL MONETARY FUND. Trade interconnectedness: the world with global value chains. IMF Policy Paper, 2013.

JOHNSON, R. C. Five facts about value-added exports and implications for macroeconomics and trade research. Journal of Economic Perspectives, v. 28, n. 2, p. 119-142, 2014.

JOHNSON, R. C.; NOGUERA, G. Accounting for intermediates: production sharing and trade in value added. Journal of International Economics, v. 86, n. 2, p. 224 236, 2012.

JONES, R. W.; KIERZKOWSKI, H. A framework for fragmentation. In: ARNDT, S.; KIERZKOWSKI, H. (Org.). Fragmentation: new production patterns in the world economy. New York: Oxford University Press, 2001. p. 17-34.

JONES, R. W.; KIERZKOWSKI., H. The role of services in production and international trade: a theoretical framework. In: JONES, R. W.; KRUEGER, A. (Org.). The political economy of international trade. Oxford: Basil Blackwell, 1990. p. 31-48.

KALDOR, N. Causes of the slow rate of economic growth in the United Kingdom. In: TARGETTI, F.; THIRLWALL, A. P. (Org.). The essential Kaldor. New York: Holmes \& Meier Publishers, 1989.

KRUGMAN, P. Growing world trade: causes and consequences. Brookings Papers on Economic Activity, n. 1, p. 327-377, 1995.

LOS, B. et al. Factor specialisation within global value chains. In: AMADOR, J.; MAURO, F. DI (Org.). The age of global value chains: maps and policy issues. London: CEPR Press, 2015. p. 48-57.

MAURER, A.; DEGAIN, C. Globalization and trade flows: what you see is not what you get! n. 12. [S.1: s.n.], 2010.

MCCOMBIE, J. S. L.; THIRLWALL, A. P. The balance-of-payment constraint as an explanation of international growth rates differences. New York: Martin's Press, 1994.

MEDEIROS, C. Inserção externa, crescimento e padrões de consumo na economia brasileira. Brasília: Instituto de Pesquisa Econômica Aplicada, 2015. 
MENG, B.; FANG, Y.; YAMANO, N. Measuring global value chains and regional economic integration: an international input-output approach. IDE Discussion Paper, v. 362, Jul. 2012.

MILBERG, W.; WINKLER, D. Trade, crisis, and recovery: restructuring Global value chains. In: CATTANEO, Olivier; GEREFFI, Gary; STARITZ, Cornelia (Org.). Global value chains in a postcrisis world. Washington D.C.: The World Bank, 2010. p. 23-72.

MILLER, R. E.; BLAIR, P. D. Input-output analisys: foundations and extensions. $2^{\text {nd }}$ ed. New York: Cambridge University Press, 2009. v. 1.

MIROUDOT, S.; LANZ, R.; RAGOUSSIS, A. Trade in intermediate goods and services. OECD Trade Policy Working Paper, Paris, n. 93, 2009.

OREIRO, J. L. et al. Restrições macroeconômicas ao crescimento da economia brasileira: diagnósticos e algumas proposições de política. Rio de Janeiro: [s.n.], 2009. (Texto para Discussão, n. 1431).

PINTO, E. C. Bloco no poder e governo Lula: grupos econômicos, política econômica e novo eixo sino-americano. 2010. 265f. Tese (Doutorado)Universidade Federal do Rio de Janeiro, 2010.

PREBISCH, R. O desenvolvimento da América Latina e alguns de seus problemas principais (1949). In: BIELSCHOWSKY, Ricardo. Cinquenta anos de pensamento da Cepal. Rio de Janeiro e São Paulo: Editora Record, Cepal, Cofecon, 2000. v. 1.

RIAD, N. et al. Changing patterns of global trade. [S.1: s.n.], 2011.

SANTOS, C. H. M. DOS et al. Por que a elasticidade-câmbio das importações é baixa no Brasil? Evidências a partir das desagregações das importações por categorias de uso. Rio de Janeiro: [s.n.], 2015. (Texto para Discussão, n. 2046).

SERRANO, F.; SUMMA, R. Demanda agregada e a desaceleração do crescimento econômico brasileiro de 2011 a 2014. . Washington: [s.n.], 2015.

SERRANO, F.; SUMMA, R. Macroeconomic policy, growth and income distribution in the brazilian economy in the 2000s. Investigacion Economica, v. 71, n. 282, p. 55-92, 2012.

SILVA, G. J. C. D. S. et al. A macroeconomia do crescimento puxado pela demanda agregada: teoria e aplicações ao caso brasileiro. In: ENCONTRO NACIONAL DE ECONOMIA, 35, Oct. 2015, p. 1-21, 2007.

SINGER, H. W. The distribution of gains between investing and borrowing countries. The American Economic Review, v. 40, n. 2, p. 473-485, 1950. 
STEHRER, R. Accounting relations in bilateral value added trade. n. 14. Vienna: [s.n.], 2013.

THIRLWALL, A. P. A natureza do crescimento econômico: um referencial alternativo para compreender o desempenho das nações. Brasília: Instituto de Pesquisa Econômica Aplicada, 2005.

THIRLWALL, A. P. Productivity and growth in manufacturing industry: a reply. Economica, New Series, v. 35, n. 140, p. 385-391, 1968.

THIRLWALL, A. P. The balance of payments constraint as an explanation of international growth rate differences. Banca Nazionale del Lavoro Quarterly Review, v. 128, p. 45-53, 1979.

TIMMER, M. P. et al. Slicing up global value chains. Journal of Economic Perspectives, v. 28, n. 2, p. 99-118, 2014.

UNCTAD. Global value chains: investment and trade for development. New York and Geneva: United Nations Publication, 2013. 